\title{
EENE OUDJAVAANSCHE POËTISCHE OMWERKING VAN HET ÂÇRAMAWÂSAPARWAN
}

DOOR

Dr H. H. JUYNBOLL.

Toen in 1893 de Oudjavaansche prozabewerking van het Âçramawâsaparwan of het vijftiende boek van het Indische epos Mahâbhârata door mij uitgegeven werd, was het mij niet bekend, dat van dit en de volgende parwan's eene Oudjavaansche omwerking in poezie bestaat, getiteld Kṛṣnântaka, d. i "Kṛṣna's dood." Dit onderwerp wordt in het Mausalaparwan of $16^{\mathrm{e}}$ boek van het Mahâbhârata behandeld, doch in de eerste zangen van het Krșnântaka getitelde gedicht wordt ook de inhoud van het Âçramawâsaparwan in hoofdtrekken weergegeven. Dr. van der Tuuk zegt in zijn Kawi-Balineesch Woordenboek, deel II, p. 90 , s. v. Kṛ̣nântaka: "S(anskrit), titel $\mathrm{v}($ an) e(en) kĕkawin, getrokken uit de Mosalaparwwa, Adip(arwa), 7, behelzende den dood $\mathrm{v}(\mathrm{an})$ Krĕsina en de zijnen; de vier laatste parwwa's zijn daarin mede verwerkt." Onder de Oudjavaansche Handschriften, die Dr. van der Tuuk an de Leidsche Universiteitsbibliotheek vermaakt heeft, is een afschrift van het Kṛ̣nântaka, no 178 (I). Dit gedicht bevat 34 zangen, in Indische versmaten. In zang I (vers $1-5$ ) wordt Rudra angeroepen: O $\dot{m}$ sang hyang parameșți Rudra [w]uningan sěmbah ning anggöng langö. In het tweede vers wordt naast Çiwa ook Brahma en 'Wiṣṇu aangeroepen: Brâhmâ Wiṣnu Maheçwara pwa wĕkas ing çâstrotta mekâkṣara. De volgende zangen zullen hier volgen, in tekst en vertaling. In de aanteekeningen zal gewezen worden op de overeenkomende plaatsen van het O. Jav. Âçramawâsaparwan. Hiervan stonden mij twee Hss. ten dienste, die nog niet in Europa waren, toen ik dit parwan uitgaf. Dit zijn de codices $3411^{\mathrm{d}}$ en $34.28^{\mathrm{s}}$ van het legaat van der Tuuk. De Oudjavaansche tekst luidt als volgt: 


\section{Zang II.}

Manggĕh manggala ning kathâ wijaya Pạ̣̣usuta ri hilang ing Suyod(h)ana, Ngkâ çrî Keçawa mamwite ṇ̣pati Dharmmatanaya muliheng swanâgara, Ngkâneng Astinarâjya sang prabhû sirândiri subhaga di nâtha ning jagat, [H]embĕh tușța manah narendra ri hanâng Pariḳsit (t)uwi wangça Pâṇ̣awa (1). Ngûnî kâla wijil nirân mati těkap dwijasutaçara dug sireng wĕtĕng, Towin pûrṇna sulakșaneka karaṇang hurip inuripa de Janârddhana ${ }^{1}$, Mangkâ çrî Dhṛtarâja Korawa lawan walu-walu'n iniwö wineh suka, De çrî Dharmmasuteki lolyana sirang huwa sumungani ratna bhojana (2) Manggĕh katwanga de narendra gurusiṣya bangun ulalahirân panĕmbaha, Harṣâmběk Dhṛtarâja nâtha mari luh nira sumawaki sang Suyodhana, Nghing sang Bhîma jugânpurik mulati tingkah i paniwi nirang nareçwara, Engĕt ngûni ri duḥka sâka ri Jatûg̣̣ha kinirakireng Suyod(h)ana (3). Yângde prih ni manah nirân pirapirang dina tinahĕna mangkin anglare, Mojar tampanahâ kitâryya Dhṛtanâgara [h]awirâng i patya ning anak, Tuṣtâmbĕk ta sinewa de nikang aweh lara mati wĕka wandhu wandhawa, Towin wut[t]a matanta tulwi ri hatinta wuta samasâmâmbĕk ing kĕnas (4). Nâhan tojar irâng Wṛkod[h]ara madĕg mûman-uman apẹḍĕs wuwus nira, Mangkin tibra lumuh nirantara manah nira lara ri wuwus Wṛkod[h]ara, Lĕnglĕng lwir kawuhan hurippamah ikang lara [h]atutur i sang Suyodana, Nâhan marmma nirâmwite ṇ̣pati mûra tapa sira ring tapowana (5). Mojar sang prabhu: He narendra tak aweh mami mura tapa ring tapowana, Tan tṛ̣nânta mangâryyakĕn kwa pakurang ni nagara rajatâdi bhojana, Lâwan mâs maṇi râja mulya kita mulya sinini pakarâma yak hiḍ̆e , Om rakryan tuwi tan kahinghani [h] asih nira laku taku haywa pâdaka (6). Âpan rakwa purih nikang dadi sujanına ratu warĕg amûktya ring prajâ. Yogyânûting ulah muniçwara kuminkina manguna tapâdi len brata, Tușțamběk naranâtha mogha manganugraha tinuduh ikang balângiring, Mwang çrî Kunti mahâ tumût tumuturâtapa mawarahi sang Yudhișthira (7). Mojar çrî ṇ̣pa Dharmmaputra tak aweh nghulun umura mareng tapowana, Tolih putra wuyut kawiryyạn apa don ika wibhawa phalang hanak daya, Om putrangku katon twangebu kapatibrata jûga kaharĕpku tan waneh, Ngûnin sang prabhu Pạ̣̣u râma lumah ing giri tumut aku mâtya ring wukir (8). Haywâ mâs kaharĕpku haywa wadakâ tapahamatapakĕn sirang bapa, Towin çabda nirang Wyasâ tĕka mangaywani wuwus ira yogya tûtana.

\footnotetext{
1 Hieromtrent leest men in het Âdiparwan: Prasiddha kâsih bhațâra Kṛșna, hinuripnirânkneng hrû sang Açcwatthâma, ri sḍĕngira haneng jro wtěng sang Uttarî. Mijil taya winastwan mahuripa de bhațâra Krșna. Vgl. Dr. Hazeu's vertaling in B. T. L. V. $6^{\circ}$ volgr. V, p. 191 en zie ook noot 2.
} 
Harṣâmbĕk ṇ̣pa Dharmmaputra sumuyng marĕk angusapi pâda sang ṛși, Sâmpun mangkana sûkṣma sang ṛ̣i sirang Dhṛtanagara huwus madandana (9). Ngkân mangkat ri tĕlas nikang wĕngi ring endjing uwus(s)aman umunggah ing ratha,

Lâwan sang Widurâryya Sañjaya saselwa laku tumuture sirang bapa. Tan warṇnân tĕka ring Wyasâçrama pirang dina lawas angiwö tapa brata, Mwang çaktindriya towi sâmpun amatěh těkap jra masamâddhi nityasa (10). Wwantěn parwwata çûnya çûci patapan nira lĕngĕng angûngang sakendriya, Endah lwir ni yaçanya wahwa wangûnan ri yawa tinatâ tĕke dalĕm, Janggâmĕmbang arûm rikang taḍahalasnya lĕngĕng asĕmu râmya ning tulis, $[H]$ anglîlângililan dwaranya'n aras ing limut asĕmu kaḍatwan ing tawang (11). Pinggir ning patapan sumar surabhi campaka kajĕnar awor lawan wungû, Handong bhang kayu kañcanâsana lawan kanigara suměkar paḍ̂sinang, Lwir wintang pakatonan ing kusuma râmya paḍa-paḍa pinanta tût tawan, Mattang satpada wibhramângrĕng angusir sěkar asĕmu pasambat ing rimang (12). Lor wetan patapan katon lěngĕng acâmara paḍa-paḍa litnya tuntunan, $[H]$ asrang pasyang i sûndarinya'n alangö hinûwuhan i paçabda ning kuwong, Kryang ning ghaṇta masanggha santi nira sang ṛ̣i kukus ing asĕp nirantara, Byakta lwir hawanân nirang ṛ̣i yadin mralaya hĕlĕm anĕmwa çûnyata (13). Râmyang kirṇna samîpa ning patapan ârjja tirisan ika tĕb lawan lirang, $[\mathrm{H}]$ açrî warṇṇa nikang pucang gaḍing awor patalěsan i hiring nikang jurang, Air tambang sumirat sake parangan ârjja tinalangan (h)ilînya tanpĕgat, Mĕmbang mopih ikang mayang lawan ikang surabhi'n inaras ing madhubrata (14). Mangkin konang-unang tikang wukir alasnya wahu paḍa tininggal ing jawuh, Angde raçmi limutnya rantunan i lambung ing acala hanan pĕgat-pĕgat, Wĕr ning pakșyangḍap-pdap [h]anĕlat ing rĕmĕng umidĕr awûk samar-samar, Tumrâng teja ning ârkka ring [H]udayaparwwata nuluh ikang açrameng gĕgĕr $(15$ )

Tan ngeh yan huningan halĕp ni patapan pạ̣a mamuhara râga ning mangö, Warṇnân çrî nọpa Dharmmaputra sasanak nira tĕka samasâma wijil nira lagi madulur lawan ratu (16).

[Nâhan çabda nire narendra nadawan wuwus irang ayu bhagya sang prabhû, Warṇnân sang tapa ring tapowana saharṣa těka paḍa manamya sang prabhu, Salwir ning phala mulya sahaneng wukir inaturakĕn sag[h]orawa, Lâwan pûja sahungkarâștawa panambrama nira saha citta nirmmala (17). Mangkin hârṣa manah Yudhișțhira tumon ṛ̣iwara paḍa kapwa sambrama, Mâs lâwan mạ̣i mulya wastra ya paweh nira kawaca mapâdukang mạ̣ik, Yekân tuștạ manah maharși ri [h]anugraha narapati bhâra yâk hidēp, Tau waktan pakulĕm nareçwara ring eñjing umulih i tĕlas nikang pětĕng (18). Tan warṇṇ̂n ri [h]ulih Yudhiș̣hira sang âryya Dhṛta manglawad,] 
Ngkâneng açrama de nirang [h]ibu huwus malawas atapa tan papangguha, Dewî Kṛ̣ụa sirang Subadra ya dulur nira mararĕm (h)uwus kṛtañjali (19), $[\mathrm{H}]$ antyan tuș̣̣a manah nirang ṇ̣pati Pạ̣ḍudayita ri ḍatĕng nareçwara, Lâwan çrî Dhṛtarâja garjjita sumambrama mapag ing ujar manohara, Om-om putra huwus katon parama dharmma nira sakala dewata krama, Yan ring deya sadeya ning ratu tatan winarawarah apan huwus tama (20). Anghing tan dadi tan lingĕnkwa ri kitânaku tulusa makirttya ring jagat, Nghing sang pâṇ̣ita dibyakantangana sâmbawa ya pinakadîpa ning praja, Yan sang bhûpati sampay ing wiku pĕtĕng paḍa nika wulan âng hilang çriya, Yâwat pâṇ̦ita çirṇna nâng prabhu wijil nira lagi madulur lawan ratu (21). Nâhan çabda nire narendra nadawan wuwus irang (h)ayu bhagya sang prabhu, Warṇnân sang tapa ring tapowana saharșa těka paḍa manamya sang prabhu, Salwir ning phala mûl[y]a sahaneng wukir inaturakĕn sag[h]orawa, Lâwan pûja sahungkarâș̣awa panambrama nira saha citta nirmala (22). Mangkin hârșa manah Yudhișțhira tumon ṛ̣iwara pạ̣a kapwa sambrama, Mas lâwan mạ̣i mulya wastra ya paweh nira kawaca mapâdukang maṇik, Yekân tușța manah mahârși ri $[\mathrm{h}]$ anugraha narapati bhâra yâk hiḍĕp. Tan waktan pakulĕm nareçwara ring eñjing umulih i tĕlas nikang pětěng (23). Tan warṇnân ri $[\mathrm{h}]$ ulih Yudhiș̣hira sang âryya Dhṛtanagara nocapěn muwah, Kâlanyân tĕka ring patirthan adulur sĕnĕug i sẹ̣ĕng irân haneng hawan, Tingkah ning dadi towi tan dadi kalingsir i samaya nikang pati’n tĕka, Pangde ning widhi sangka ring dawalang agni mĕtu sinirir ing samîrana (24). Mangkin wṛddhi dilahnya'n ujwala těkânggěsĕngi kanana sâdu mangliput, Tan wring daya nirâryya Sañjaya tĕkap nira bapa laku tan wĕnang gyakĕn, Byaktang mâtya tĕkap hyang Agni manangis mulati kasiharĕp nirang bapa, Mojar çrî Dhṛtarâja: "Sañjaya bapangku laku sihana tâku taryyakĕn (25). Pĕngpĕng tapwa ḍatĕng hyang Agni palarĕn hurip anĕmuha çûddha ning hiḍĕp. Nâhan ling nirang âryya Sañjaya hilang $[\mathrm{h}]$ asih ira $[\mathrm{h}]$ inaweșa ning takut, Lunghânglĕs Himawân wukir ya pinaran nira layu kawěkas sirang bapa, Mwang sang Gandhari Kuntabhojatanayânana ginĕsĕng ikang mahânala (26). Yekân çoka sapaṇḍawâjarira sang ṛ̣̦i Narada ri patya ning [h]ibu, Ling çrî Dharmmasute hyang Agni lalu nistura nirang ibu tapwa râkṣaka, Ngûnî̀ndug rika Kaṇdawâ[w]wana si [H]arjjuna [h]asiha sumung [ha]bhojana, Towi pwâ ri huyung surendra sira râkṣaka ri warayang âryya Phalguna (27). 
De tekst van bovenstaand gedicht is te corrupt, om eene volledige vertaling toe te laten. Bij het ontbreken van een tweede Hs. zijn emendaties eenigszins gewaagd. Daarom zal ik mij hier beperken tot eene uitvoerige iahoudsopgave of ontleding.

1. Na Suyodhana's (of Duryodhana's) dood vraagt Keçawa (d. i. Kṛṣna) aan Dharmmatanaya (of Yudhișthira) verlof, om naar zijn rijk terug te keeren.

2. Dhṛtarâjya (zoo leze men voor Dhṛtarâja) of Dhṛtarâșța wordt met eerbied behandeld door Yudhisthira.

3. Dhṛtarâșța's verdriet begint te verminderen. Alleen Bhîma blijft verbitterd op hem bij de gedachte aan het verdriet en de rampen, die Suyodhana over de Pâṇawa's gebracht heeft met het Jatugrha of huis van lak. Dit vers stemt overeen met het begin van het Âçramawâsaparwan. Ook daar wordt gezegd, dat Wṛkodara (of Bhîma) Dhṛtarâșța vijandig gezind blijft (anghing sang Wṛkodara juga tan anggâpratipratyaya y a tika jũâna pratikûla enz.) Daar wordt echter niet gezegd, dat Bhîma vertoornd is bij de gedachte aan het Jatugṛha, maar bij de gedachte aan de verbanning van de Pâṇ̦awa's naar het woud en de schande, die Draupadî aangedaan was en de vernederingen, die de Pânḍawa's zich moesten getroosten tijdens hun verblijf in Wirâța's rijk.

4. Bhîma doet Dhṛtarâsțra verwijten. Regel 3 van dit vers kan men vergelijken met de volgende woorden in het Âçramawâsaparwan: Menak pwa pintajâ dening winehnya larâmbĕk, suka pwa kinabhaktyan de nikang huw us manĕmu lara denyu? De vierde regel van dit vers is te vergelijken met de woorden: Kita ya-ta sang wuta tke hatinta en de laatste woorden van regel 3 (mati wĕka wandhu wandhawa) zijn de vertaling van de laatste woorden van çloka $69 x$ van den Sanskrittekst: Hatạ̣ sasutabândhawạ̣ (gedood met zonen en bloedverwanten).

5. Dit heeft ten gevolge, dat Dhṛtarâșțra aan Yudhișthira verlof vraagt, om zich naar een tapowana (kluizenarij) te begeven.

6. Yudhisthira wil hem dit eerst niet toestaan.

7. Eindelijk stemt hij echter toe. In het Âçramawâsaparwan geschiedt dit eerst, als W y âsa Dhṛtarâsțra's verzoek ondersteunt en nadat Dhṛtarâșțra eerst gezegd heeft, dat hij zich anders van het leven zal berooven door niet meer te eten.

8. De eerste regel van dit vers is corrupt en moet vervallen. 
Het is slechts eene herhaling van vers 6 , regel 1 . Het volgende (regel 2-4) moet vroeger staan, daar dit woorden van Dhṛtarâșțra tot Yudhișthira zijn. In regel 4 zegt Dhṛtarâștra, dat hij evenals Paṇdu in het gebergte wil sterven.

9. In dit vers worden verhaald, hoe Yudhisțhira zich door Wyâsa laat overhalen, om Dhrtarâștra toe te staan, naar het woud te gaan.

10. Widura en Sañjaya vergezellen Dhṛtarâșțra. In het Âçramawâsaparwan worden eerst uitvoerig de raadgevingen opgesomd, die Dhṛtarâștra aan Yudhisthira nalaat, waarbij vele Sanskritverzen aangehaald worden (çloka 187b-190b, 220a, 224b, 232a, 246, $250 a$, 283, 289b, 329a, 330, 331 a, 341). Dan wordt daar verteld, hoe een offer gebracht wordt aan de schimmen der overledenen, waarvoor belangrijke sommen besteed worden, ondanks Bhîma's tegenstand. Ook Kuntî gaat mede (dit wordt hier reeds in vers 7 gezegd). Dhṛtarâș̦tra komt eerśt bij den ziener Catay ûpa, wiens naam hier niet voorkomt. Hier vindt men echter eene zeer uitvoerige beschrijving van Wyâsa's kluizenarij, die in het Âçramawâsaparwan niet voorkomt. Deze beschrijving vormt den inhoud van vers 11 tot 15 .

Vers 16 is corrupt, zooals reeds blijkt uit het feit, dat er twee regels aan ontbreken en de $2^{\mathrm{e}}$ regel 9 lettergrepen te veel heeft.

Vers 17 tot vers 19 , regel 1 wordt herhaald in vers 22 , tot vers 24, regel 1. Natuurlijk moet dit gedeelte slechts eens staan in het gedicht. In regel 1 van vers 19 is de tekst corrupt: sang âry y a Dhṛta manglawad. In regel 1 van vers 24 staat beter: sang âry ya Dhṛtanagara nocapĕn muwah. Vers 17 en 19 zijn eene anticipatie op vers 22 en 23. De eerste regel toch van vers 17 (nâhan çabda nire narendra) slaat niet op het voorafgaande in vers 16 , regel 2 , maar wel op regel 4 van vers 21. Op regel 2 van vers 16 moet dus regel 3 van vers 19 volgen. 20-21. Bezoek van de Pâṇ̦awa's aan Dhṛtarâștra. De woorden, die de laatste bij deze gelegenheid spreekt, komen in inhoud hoofdzakelijk overeen met wat men vindt in 't Âçramawâsaparwan, p. 57.

22-23. Yudhiṣthira schenkt goud, edelgesteenten en kostbare kleederen aan de kluizenaars in ruil voor de vruchten en wortels, die hij van hen ontvangt. Dit komt overeen met p. 58 van 't Âçramawâsaparwan. In dit gedicht wordt niet gesproken over Widura's dood, die in den prozatekst voorafgat.

24-25. Reschrijving van Dhṛtarâșțra's dood tengevolge van een boschbrand. De boschbrand wordt in regel 4 van vers 24 aangeduid 
door dawala ng ag ni. In vers $1029 a$ van den Sanskrittekst staat dâw âgnir en in de Oudjavaansche vertaling dâwânala.

26. Sa ̃̃ja y a laat bij die gelegenheid Dhṛtaràștra in den steek en vlucht naar den Himâlaya. Dit vindt men ook in 't Âçramawâsaparwan, p. 66: Malayû ta sang Sañjaya, mungsir sang hyang Himawân. Men kan zeggen, dat de $4^{\text {e }}$ regel van dit vers eene paraphrase is van de woorden: Kunang Dhritarâșṭa, sang Gândhârî, sang Kuntî, ya-ta kagsĕngan de sang hyang Agni in den prozatekst (p. 66).

27. In dit vers verwijt Yudhișthira aan god Agni zijne onmeedoogendheid, terwijl toch Phâlguṇa hem vroeger een dienst bewezen heeft bij het verbranden van het $\mathrm{Kh}$ hṇ̣ ạ a-woud. Dit vindt men in 't Âçramawâsaparwan op p. 67: Sंang Phâlguṇa arddha ${ }^{1}$ tika pamújanta ri sang hyang Agni.

\section{Taalkundige Aanteekeningen.}

1 , regel 4. De $h$ van $\mathrm{h}$ e $\mathrm{mbĕh}$ moet wegvallen, want ĕm beh is samengetrokken uit $\mathrm{a}+\mathrm{imb} \mathrm{m}$ h. Het praefix $a$ drukt hier uit, dat het verbum intransitief is, evenals b ĕr in het verwante Maleische woord bĕrtaıbah. Het Nieuw-Javaausche woord voor "vermeerderen, toenemen" is imbuh, Ng. wĕwah, K. De wortel is bĕh, bah, wah of buh.

2 , regel 1. Voor dug leze men $\mathrm{duk}$ "toen."

Regel 3. Dhṛtarâja is verkeerd. De gewone naam is Dhṛtarâștra, maar ter wille van het metrum kan dit Dḥ̣tarâjya worden, zooals hier, of Dhṛtanagara, zooals in vers 4 en op andere plaatsen.

3, regel 2. Sumawaki schijnt hier te beteekenen "betreuren, beweenen" of iets dergelijks.

Regel 4. Kinira-kira beteekent hier "bedrogen worden." Evenzoo in het Oudjavaansche Râmâyạ̣a, XIV, 53: Ring dangû hana musuh kinira-kira, hetgeen de Balineesche interlineaire vertaling weergeeft met: Dening ne suba ada çatru gawenang daya.

4, regel 3. Wandhawa is eene minder juiste spelling van

1 Voor arddha leze men wyartha dahat, zooals uit de andere Hss. blijkt. Hierdoor wordt de vertaling (p. 124, r. 1): Phâlguna, gij hebt god Agni tevergeefs geprezen. 
bândhawa (Skr.) "bloedverwant." Op dezelfde wijze wordt het geschreven in het Oudjavaansche Râmâyana, VI, 172, waar de Balineesche interlineaire vertaling terecht "kadang" heeft. Ook in het hedendaagsch Javaansch luidt het wandawa of wand a wa.

5, regel 1. Apĕdĕs wordt hier figuurlijk gebruikt als "scherp" van iemands woorden. Evenzoo in het Râmâyaṇa, VIII, 125: Sumahur saniṣțura ujar nirâpẹdĕs, Balineesch: Masahut tanpaçruti muñindane sĕpět.

Regel 2. Lumuh is eene nieuwere vorm. De echte Oudjavaansche vorm is lĕmĕh, dat o. a. voorkomt in het Râmâyana, VIII, 181, XIII, 23; a lĕ mĕh vindt men l. c. VI, 52, XX, $49, X, 44$, III, $47, \mathrm{~V}, 55$; a lĕ mӗha: III, 52,82 ; malĕmĕh: VI, 135, VIII. 244, enz.

Regel 3. Kawuhan hurippamah. Deze plaats is mij duister. 6 , regel 1. Tak aweh. Uit deze plaats blijkt duidelijk, dat tak hier beteekent "tan ak u." De verkorte vorm wordt gebruikt, omdat de nadruk niet valt op aku, maar op tan. Andere voorbeelden vindt men o. a. in het Râmâyana, V, 15: Y an ika jugânakĕbya tak angipya waneha ta ya, waar de Bal. vertaling tak angipya weergeeft met: norana ngipiang. $V$, 50: Sahana nikang watěk Raghu kabeh tak anon alay $\hat{u}$, waar tak anon weergegeven wordt met: dereng kapánggih. V, 58: Aku tak angön-angěn laki waneh sira tunggal atah. (Balineesch: Kahi nora enz), XVII, 36: Tak adoh aku sake sukunta natha. (Bal. nora pasah tityang enz.), XIX, 24: Sangke doṣangku'k anglĕs mara ri kita alah tibra mahyuntak amwit, I, 55: Tak anumoda yar paminta çarạ̣angke, XXI, 89: Deni tûtta saparanku tak angluk, XXIII, 79: Tak aharĕp ing hurip pati patĕmwaning sang bhuwana, IV, 62: A pa tak perung irangku tan sipi enz. Vgl. ook Prof. Kern's Proeve uit het Oudj. Râm. in het Feestnummer der Bijdragen, p. 21.

Regel 3. Râja mulya. Hiervoor misschien te lezen: râjatulya (Skr.) "een vorst waardig, betamende." Intusschen is mûlya, prijs, nauw verwant met argha en arhati, zoodat râjamulya z. v. a. râjârha kan wezen.

Regel 4. Voor pâdaka leze men bâdhaka. Dan beteekenen de laatste woorden: Ik verzet mij er niet tegen. Vgl. vers 9 regel 1 .

8, regel 2. Wuyut beteekent "kleinzoon," evenals het Maleische "buyut." 
Regel 4. Lumah beteekent: "Ligt begraven;" eigenlijk hetzelfde woord als Jav. lumah.

10, regel 3. Angiwö (vgl. iniwö in vers 2). Omtrent dit woord heb ik vroeger reeds gezegd ${ }^{1}$, dat het beteekent "bedienen, eer bewijzen, onthalen, op prijs stellen, zich toeleggen op (Skr. niṣewate)" en dat het verwant is met Tag. ibig "willen, beminnen, verlangen" en Bulusch iwě. Ook in het Râmâyana komt het dikwijls voor, b.v. XIII, 30: Apâg uṇ̂aningwang ahöm tĕwas iwö? De Balineesche vertaling geeft iw ö hier weer door abot. Het passief iniẅ̈ komt voor Râm. VII, 45, waar tevens de actieve vorm angiwö te vinden is: Jâtî mụ̂ha minitra tan wruh iniwö tan ngeh gumantyângiwö (Bal. vertaling: tingkah i bog masumitra tan ngĕh kaingû norana nahur panging $\hat{)}$ ). Hier beteekent het "weldoen, welgedaan worden." Verder XIII, 31: Mangke pwa yan mânuṣa çatru yeniwo, waar de Bal. vert. ten onrechte kakewĕhang als vertaling van iniwö geeft. Râm. VII, 38: Parigraha jugen iw önya tar angĕnnangĕn mitra ya. Bal. vertaling: mangwiçeṣa kewala pangingûnya nora pangrasana ring kanti. De Gerund. vorm iwön komt voor Râm. XIII, 34: Tatan iwön tan sapahö makěna ya. Bal. vertaling: norana rahat nora sĕḍ̆ng rawosang ikang daya. Deze vertaling is verkeerd. Het beteekent: ter harte te nemen, of Duitsch "beachten," Skr. âdriyate. Ten slotte Râm. XXIV, 201: Swastâ ning bhuwanatrayekana iwön nâhan phalantât jaya. Bal. vert. rahayu ning trilokane punikâ patěpěkin mangkana phalana cahi molih. Zie verder dr. van der Tuuk's Kawi-Balineesch Woordenboek, I, p. 235 s. v. iw ö.

Regel 4. A matĕh tĕkap ira enz. Hier bekleedt tĕkap dezelfde funetie als in tegenwoordig Javaansch den of ěnggon. Volgens Winter's Kawi-Javaansch woordenboek is patěh het Javaansche luluh, lĕbur, abdi. Hier beteekent het: zich bedwingen, zich beteugelen, zich in toom houden enz.

11, regel 3. Tadahalas. Dit woord is mij onbekend.

Regel 4. Deze regel is mij duister.

12, regel 1. Kajĕnar van jĕnar, een Kawiwoord, dat "geel" beteekent.

13, regel 3. Kryang beteekent "gerinkel." Vgl. dr. van der Tuuk's Kawi-Bal. Woordenboek, II, p, 102, s. v.

\footnotetext{
1 In mijn proefschrift, pag. 207.
} 
14, regel 2. I hiring. Hier is hiring blijkbaar met een h geschreven. Evenzoo in Râmâyana XIX, 106: ahiring. De beteekenis van hiring is: "kant, opstaande zijde, helling." 'Zie verder dr. van der Tuuk's Kawi-Balineesch Woordenboek, s. v. hiring.

Regel 3. Tinalangan. In het hedendaagsch Javaansch beteekent nalangi, waarvan tinalangan het passief is: "iets van een goot voorzien." Hier beteekent het: "er langs geleid" of iets dergelijks.

Regel 4. Mopih van upih. Dit beteekent tegenwoordig "de bladschede van den pinangboom." Voor ngupih vindt men: "als ungih." Dit woord ontbreekt in het Javaansche woordenboek van Vreede. Verder: "nl. bol, v. e. dikken, vooruitstekende buik." Dr. van der Tuuk geeft in zijn Kawi-Balineesch woordenboek de beteekenis niet op, mar wel parallelplaatsen, b.v.: Mopih wâhwa mayang ri hati ning mulat en mupih-upih alis tikĕl. (Sum. 60, 4). Uit deze plaatsen zou men opmaken, dat het beteekent "zich buigen, zich krommen" of iets dergelijks.

20 , regel 1. Antyan is eene verbastering van atyanta (Skr.) "buitengewoon, bovenmatig, zeer." Dit werd eerst a ntyanta en daarna anty an, omdat men ta voor het Javaansche gelijkluidende woord aanzag, niet wetende, dat at y a n ta bestaat uit het praefix ati en het substantief anta (einde.) Van antyan makte men zelfs mantyan, in de meening, dat a het bekende Javaansche praefix was, dat door ma vervangen kan worden. Zie van der 'Tuuk's Kawi-Balineesch Wdb. s. v. antyan.

22. regel 2. Manamya van namya. Dit is eene afleiding van nam (Skr.) "buigen, eerbied betuigen." Van nam is ook het bekende pranata afgeleid, dat zoo dikwijls in het Oudjavaansch voorkomt. Zie ook dr. van der Tuuk's Kawi-Balineesch Woordenboek, s. v. nâm y a.

23, regel 4. Pakulĕm beteekent hier: "de wijze, waarop (de vorst) de nacht doorbracht." $\mathrm{K}$ ulĕm in de beteekenis van "nacht" komt dikwijls in het Râmâyana voor, b.v. II, 66: Lunghâng kulěm rahina kâla wijil hyang ârkka (Bal. vertaling: liwat pĕtĕnge diwasa sẹdĕk mĕdal hyang rawi), VII, 21: Moni tarpahuwusan rikang kulĕm (Bal. vertaling pĕtĕng), IV, 25: Kramakâla umeh kulëm tĕkâ (Bal. vertaling: tingkah diwasa das wĕngi rawuh), IV, 26: Rahinanya atîta tang kulĕm (Bal vertaling wĕngi), VIII. 36: 
Rikanang kulĕm suka ya mâmĕng-amöng. (Bal. vertaling: Hana ring wĕngi lěga ya maeangkrama), XX, 78: Kapwâmangan manginum magoști ring kulĕm (Bal. vertaling wĕngi), XI, 89 :...tuwi nikanang kulömatanghi (Bal vertaling: Wyakti hana ring ratrîngĕndusin): Ook in het Oudjavaansche Mahâbhârata komt kulĕm in de beteekenis van "nacht" dikwijls voor, b.v. Wirâtaparwan f. 11, Udyogaparwan f. a, 11, Swargârohanaparwan f. 76 enz. Verwante woorden zijn het Oudjavaansche tilĕm, Jav. malĕm, Mal. mala mn enz.

24 , regel 3. Kaling sir schijnt hier niet te beteekenen: "voorbij den middag, over den tijd," zooals in het hedendaagsch Javaansch, maar: begon te naderen tot.

26 , regel 2. Inaweșa is een passieve vorın van aweșa, eene verbastering van âweça (Skr) "het ingaan." Men kan het hier vertalen door "bevangen door." De vorm inaweșa komt ook voor Udyogaparwan f. 7. Kâweṣa vindt men in het Âdiparwan, f. 129: Kâweṣa ta sira dening râkṣasa. Daar beteekent het: "bezeten door een râkşasa" In het Skr. zou men zeggen: âwiṣthha. Ook in het Râmâyana vindt men kâweșa, XVII, 32 : Kadi kâweșa Banaspati'n sirâtah (Bal. vertaling: lwir kasusupan Banaspati ida ika. De vorm añaweșa komt voor Âdiparwan, f. 129 in de beteekenis van: in te gaan (om bezeten te worden). Ook Wirâtaparwan f. a, 17 en Râmâyaṇa XXI, 64: Grahagaṇa gaṇa bhûta yângaweșa (Bal. vertaling: yen rahu gaṇa agöng bhûta ya ngawiçeșa). Mangaweṣa vindt men Râmâyana $\mathrm{V}, 54$ : Ikanang asih takut y a mangaweșa rikang hṛdaya (Bal. vertaling: punika lulute wĕdine ya ngawatěk ikang manahe). De vorm pangâweṣa wordt gevonden in Râmâyaṇa XXIV, 231: Ri pang âweșa nikângunĕng-unĕng ya (Bal. vertaling: dening pangwiçeșan ikung rimang smalihnya). Vgl. ook dr. van der Tuuk's Kawi-Balineesch Woordenboek, I, p. 250, s. v. âweça.

Regel 3. Anglĕs. De wortel lĕs beteekent "weg," b v. Râmâyaṇa, XXIV, 3: Âgneyâstra panah apuy pwa pamalĕs sang Râma lĕs lîna ya (Bal. vertaling: Agni astra sañjata api ika pangwalĕs sang Râma raris hilang ika). Hier staat lĕs voor lîna, dat hier de beteekenis heeft van antarlîna (verdwijnen), zooals ait de Bal, vertaling (hilang) blijkt. Evenzoo gebruikt men in het Sundaneesch lĕs als redewoord voor löngit (verdwijnen). Over de verbinding jag lĕs zie men mijn proef- 
schrift, p. 177. Alĕs beteekent "zich verwijderen" in Râmâyaṇa, III, 15: Wanguṇ-ḍahina çîghra minggat alěs ta sang Râghawa (Bal. vertaling: di das lĕmahe glis matinggal manilib ida sang Râma). Dezelfde beteekenis heeft anglěs hier. In het tegenwoordige Javaansch beteekent het: "diep slapen, diep getroffen of aangedaan zijn." De wortel lĕs beteekent nu "in eens weg raken, in slaap of in een flauwte vallen" en nglělĕs "dommelen, insluimeren; ben. van een ziekte, aan den invloed van een booze geest toegeschreven." Bij de laatste beteekenis dacht men zich waarschijnlijk, dat de ziel het lichaam verlaten heeft door den invloed van booze geesten, welke voorstelling men nog vindt bij de Bataks, Dayaks enz. ${ }^{1}$.

27, regel 3. Kaṇḍawâwana. Hiervoor leze men: Khânḍaw a-wana (Skr.) "het Khânḍawa-woud." De brand ran dit woud wordt beschreven in het laatste gedeelte van het $\hat{A} d i p a r w a n$, dat vandaar $\mathrm{Kh}$ âṇawadahan a parwan heet (vers 8050 - 8479). Dit gedeelte is reeds in deze Bijdragen beschreven door dr. Hazeu

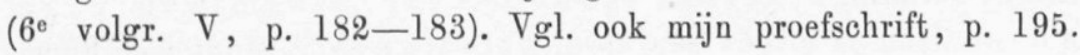

Thans volgt de Oudjavaansche tekst van zang 3 vau het Kụṣ̣ântaka: (metrum Çârdûlawikrị̂̂ita).

Nâhan çabda nire hyang Agni maněsĕl mojar sirang Nârada: "Om putrangku hade wuwusta tuwi tan mangkâ prawṛtteng apuy, Towin râkṣaka rẹ̣a sang mati matangnyekân pějah reṇaji,

Dening yoga mijil tang agui riyawak çînṇ̂nanggĕsĕng sâkṣaṇa (1). Lâwau haywa narendra çoka ri pějah reṇanta ring açrama, Lâwan çrî Dhṛtarâș̣̦ra sâmpun ayaçîng dânâdi lâwan brata, Yogyâyogya nike narendra gawayĕn sang matyaweh tarppana, Lumrekang paradâna puṇya katěke çewâdi len çogata" (2). Nâhan ling ṛ̣i Nârade ṇ̣pati harṣâmběk nirângañjali :

"Singgih sâjña maharṣi tad wihang apan yogyân [h]ujartenghulun, Nghing sih sang ṛ̦i ngeratonakĕn ikang dâno(†)tameng rât kabeh, Sámpun kobhaya de maharși panaḍah çrî Pâṇ̣uputra prabhu (3). Lumrang çabda narendra ring bala lawan mantryâdhikâryyang gawe, Çîghrâpan ratu cakrawarttya těka tang gawyâyu sopâkara, Mwang sang brahmana siddhimantra paḍa tàmûjâ humung ghûrṇ̣ita, Pûrṇnâng yajña narendra wah paḍa nikang mâs len maṇik bhojana (4).

1 Vgl. Wilken, Animisme (Indische Gids, VI, 1), p. 933 en 935 sq. 
Tatkâlan ri tĕlas nikang yaça madĕg mûkṣ̂a sirang Nârada, Mwang sang brahmạ̣a çewa çogata paḍâmwit mungsir ing [h]açrama, Tușțîmběknya ri lâbha mulya nguniweh tang peka tușțang manah, Dening yajña narendra lumra miběking rât lwir hudan ring langit (5).

Het begin van dezen zang komt overeen met pag. 68 van het Âçramawâsaparwan: "Mangkana, sâjũâ haji mahârâja Yudhiṣthira," ling maharṣi, "haywa tâlara enz.

1 , regel 1. M anĕsěl. In het Oudjavaansch heeft sĕsĕl niet de beteekenis van "dichtmaken, ergens in- of tusschen kruipen, zich verstoppen," zooals in het hedendaagsch Javaansch, evenmin die van het Maleische s ĕsal (berouw hebben), maar het, beteekent "verwijten," evenals het Sundaneesche sösöl, het Bugineesche $\mathbf{s}_{\mathrm{a}}^{e} \mathrm{saq}_{\mathrm{a}}^{\mathrm{q}}$ en het Balineesche sĕlsĕl. Voorbeelden hiervan zijn : Râmayâna XXI, 32: Sĕsĕlik ang dewata lawan swakarmma (Bal. vertaling: ̃̃ ĕlsĕl ikang widhi makamiwah pagawene). Hier is sĕsĕl een absolutief. Man ĕsĕl vindt men Râmîyạ̣a $\mathrm{V}, 3: \mathrm{Ri}$ sira ta sang Daçânana masö ya mahâ manĕsĕl (Bal. vertaling: ring dane ika sang Râghawa mara ya misadya masĕlsĕlan). XXII, 4l: Nâ ling sang ari Kumbhakarṇṇa manĕsĕl makrodha sang Râwana (Bal. vertaling: Mangkana ujar sang ari Kumbhakarṇna nañĕlsĕl lĕwih gĕlĕng sang Daçîsya), Sumĕsĕl beteekent "beklaagde zich, bezwaarde zich" in Âdiparwan; fol. 151. (ri "over").

Regel 2. Hade beteekent hier "verkeerd, onjuist." In dezelfde beteekenis koint het voor in het Ràmâyaṇa, V, 48: Sira karikânangis syapa wĕruh ta kunang ya hade (Bal. vertaling: ida ke nangis sapa sira uning manawi te boya). Hier beteekent het "niet zijn." Vgl. dr. van der Tuuk's Kawi-Balineesch Woordenboek, I, 153, s. v.

2 , regel 3. Tarppa ṇa (Skr.) beteekent "bevrediging" en "offer ter bevrediging (van de schimmen der overledenen)." In het Âdiparwan heeft de Conj. vorm tarpanakĕna de beteekenis: "(indien) het gebruikt wordt als middel, om te voldoen." De vorm t u marpaṇa komt voor in het Âçramawâsaparwan, p. 67. Men kan regel 3 beschouwen als eene omwerking van deze woorden van het Âçramawâsaparwan: Manggawaya udakatarppạ̣a kita, angilyakna piṭ̣piṇ̣a, waar udakatarppaṇa beteekent: "bevrediging met waterplengingen." 
Regel 4. Voor çogata leze men Sogata. Dit is het Skr. woord $\mathrm{Saugata}$, dat Buddhist beteekent. Het staat tegenover Çewa, het Skr. woord Çaiwa, d. i. aanhanger van C iwa.

3, regel 2. Tad wihang. Vóór woorden, die met w beginnen, neemt tat den vorm tad aan, b.v. Râmâyana, XXVI, 2: Tad wulat (Bal. vertaling: twara mawâs). Evenzoo XVII, 67 en XXI, 39. Verder XXIV, 197: Tad waluya (Bal vertaling: hĕḍa malih).

Regel 3. Deze regel is corrupt.

5, regel 3. Peka is het Perzische paika, overgegaan in 't Hindustani als paika. Het komt in 't Oj. voor o. a. BhârataYuddha 444; 580; Hariwangça fol. 47, a; Bhoma-k. i37, 9; 192,$1 ; 4$. Het laat zich ook vertalen met "gemeen soldaat."

\section{Zang IV van het Kṛṣnântaka.}

Byâtîtan gati tușta ning bala muwah tucapa ta sira sang Yudhiṣthira, Sâkṣ̂t hyang Girinâtha dharmma paramartha nira kaçita ring purantara, Swastâng rât ta nanâng musuh wĕdi ri çakti nira sira bhaṭ̂na ning jagat, Mwang çrî Keçawa Wiṣnumûrtti sakalândiri saphala pangöban ing jagat (1). Ndáh mangkin waluyâng kṛtang bhuwana durjjana mari mangulah kadurjjanân, Kapwânût ing ulah munîçwara raṣagama ya paḍottameng mara, Nâhan hetu nikang jagaddhita taman kataman apara ring [h]ulah dudu, Mwang sang brâhmaṇa Çewa Çogata sameling ulah ira ri tatwan ing dadi (2). Tan warṇṇ̂n ri lawas nareçwara miwö bhuwana tĕka patang puluh tahun, Sangke lyus ni pějah Suyodana těkang Kaliyuga ri sirang watĕk Yadı, Âpan ngûni sirâdi ning guṇa suçîla masih i sira munîçwara,

Ndan mangke pramadeng munîçwara ya kârạ̣a manana ri çâpa sang ṛ̣i (3).

Het begin van dezen zang komt overeen met de volgende woorden van het Âçramawàsaparwan: Tan u capěn maharși, wuwusĕn mahârâja Yudhiṣṭhira (p. 68).

1, regel 2. Kaçita is het Skr. woord kâçita "zichtbaar, glanzend gemakt." Het beteekent hier "beroemd."

2 , regel 1. Kṛta beteekent hier reeds hetzelfde als in het Nieuwjavaansch: "rustig, in vrede, veilig," doch hier is het een substantief. De Kṛtayuga stat als een gouden eeuw tegenover den daarop volgenden Kaliyuga. 
3, regel 2. Sangke lyus beteekent hier "teu gevolge van." In Winter's Kawi-Javaansch woordenboek wordt ly us gelijkgesteld met tulus, sarĕng en tumut. Het is verwant met Dayaksch lius (weggaan). In het Âdiparwan f. 110 vindt men kîly us in de beteekenis van "op de vlucht geslagen": Kâlyus tanpanolih. Een geheel ander woord is lyus, waarvan afgeleid is malyus, dat voorkomt in het Râmâyaṇa, VIII, 76: Lâwan bâhu rwang puluh yeka mâlyus (Bal. vertaling: miwah tangan dwang daça punika paslengkat) en XIX, 113: Gaḍingnyan atitikṣna malyus alungid (Bal. vertaling: dantanya dahat mangan marostajĕp). Alyus komt voor XII, 44: Bâhuntâlyus lobha hatingku' gwulatî ya (Bal. vertaling: tangan idewa lĕmuh luluh mamingatonang ika). XXI, 198: Âmbĕknyâlus tan imbâ mangangĕnangĕn ikâ çrîmahârâja tan len (Bal. vertaling: Hiḍ̆pnya pragat nora gingsiran ne knĕhknĕhange punika sang prabhu tan mari. XXV, 79: Rahayu malantas wĕtis akilâlyus (Bal. vert. Bĕcik mĕros bĕtĕk batis makĕḍep rurus.)

Uit het bovenstaande blijkt, dat zang 2 tot het slot van zang 4. van het Kṛnnântaka (vers 6 tot 40) den inhoud van het $\hat{\Lambda}$ çramawâsaparwan weergeeft. Het Leidsche Hs. 3134 was bij mijne uitgave van dit parwan het eenige, waarover ik destijds beschikken kon. Daar dit Hs. echter eenigszins geschonden is, zijn er in mijne uitgave eenige hiaten, die thans aangevuld kunnen worden door vergelijking met de Hss. die aan dr. van der Tuuk toebehoord hebben. Vooreerst vertoont het Sanskritvers, waarmede dit parwan begint, een hiaat. In de Hss. van dr. van der Tuuk is dit vers even corrupt als in cod. 3134, n.l. in cod. $3428^{8}$ : Açwama pinggâlajaṭâpadwakapaḥ, pranggupaṇ̣akṛṣnâtukuribhauah, sarwwaçlokapậayamarṇnah kawimuk kạ̣ sarwwagâmalamwiwrthanyeti. Dan volgt: yyuwus ning Açwamedayajũaparwwa, tumut tang açramawaçâparwwa, kaping limawlas parwwa, yata ikâ pintonakna caritanya.

In cod. $3411^{d}$ leest men na het gewone Awighnam astu: A çwamaḷ pinggâlajaṭapadwakâmaḥ, pranggupaṇ ḍak rsṣntukuridanaḥ, sarwwaçlokâpa ḍayamanạ̣ kawimûktạ̣, sarwwagâmalamwi ç̣thorti. Y y u w us ning Açwame- 
da yajũaparwwa, tumûtang Açramawâsaparwa kaping limawlâs ing parwwa, yata ikâ pintonakna caritanya.

Men ziet dus, dat de lezing van het Sanskritvers in deze beide Hss. even corrupt is als die van cod. 3134. Tevens ziet men, dat voor wadayajñaparwwa niet Ityaç uitgevallen is, maar ry y uw us ning A ç. De beteekenis blijkt evenwel dezelfde. Alleen begint nu de nazin bij tumôt en de vertaling luidt dus: Na het einde van het Açwamedhaparwan volgt het $\hat{A} c ̧ r a m a-$ wâsaparwan enz. De naam Âcramawâsa komt ook voor op het einde. De lezing in cod. 3134 Âçramawasana is waarschijnlijk onjuist. In het Sanskrit-Mahâbhârata heet dit parwan Âçramawâsika. Ook de lezing kang ping limawlas in cod. 3134 is verkeerd. Hiervoor leze men kaping limawlas. De vorm kang is geen Oudjavaansch. Tevens blijkt uit de beide andere Hss., dat men yâkti in cod. 3134 niet moet verbeteren in $y \mathrm{ukt}$, maar in $y$ a ta.

Op p. 34 van het Âçramawâsaparwan (f. 2) zijn twee lacunes: Kadang sa:....n ri kita ta kabeh en yapwan.... kna. Uit cod. $3428^{\mathrm{s}}$ en $3411^{\mathrm{d}}$ blijkt, dat men dit moet aanvullen tot: Kunang samaya ninghulun ri kita ta kabeh en yapwan hanâ sira gumawayakna en de komma hierachter moet vervallen. Er volgt onmiddellijk op: wuwus tan enak i sira enz. De vertaling van beide plaatsen wordt: "Maar ik maak een afspraak met u allen" en: "als er iemand is, die woorden uit, welke hun onaangenaam zijn.

Ook op p. 35 (f. 3) zijn twee lacunes: Mangan i mik... daḳṣina en kunang sangka... makaka. Dit moet men aanvullen tot: Mangka nimita udani en de komma achter da kṣ̂ina vervalt. De vertaling is: "Dit geschiedde met medeweten van" enz. Op de tweede plaats zijn de. woorden: ri bhakti nikang uitgevallen. Uit mijne vertaling: "uit eerbied jegens zijnen ouderen broeder" blijkt, dat ik deze conjectuur reeds gemakt had.

De lacune op p. 36 (f. 4): Mengĕt i nghulun lak.... ya nyanak ni nghulun sang Duryodhana moet aangevuld worden tot: Mengět nghulun laki ri kadûrnayanyanak ni nghulun sang. Duryodhana. Dit laki, zooals cod. $3428^{\mathrm{s}}$ en $3411^{\mathrm{d}}$ lezen, verbetere men in $1 \mathrm{aku}$. De vertaling is dan: Ik herinner mij de wijze, waarop mijn zoon Duryodhana zich misdragen heeft. 
De lacune op p. 37 (f. 5) tusschen mahârâja Dhṛtarâṣṭra en gasahasrena is door mij reeds aangevuld tot: Y asya nâgas a has reṇa. Uit cod. $3438^{\mathrm{s}}$ en $3411^{\mathrm{d}}$ blijkt ten overvloede, dat dit zoo moet zijn. Dit Sanskritvers (çloka 123 van den Sanskrittekst) luidt in cod. $3428^{\mathrm{s}}$ : Y as ya nâg âsahaçrana daçasatyana we țali (sang prasiddhâ kâdi kâçaktin ing liman sayutta), soya narim âwyaçritya çewâ râjya natasuwat. In cod. $3411^{d}$ : Y asya nâgâsâhaçrâna daçasatyana we wâli (sang prasiddha kâdi kâsaktin ing liman sayutta), so ya narim âwyasçritya çewo rajya datasuwat. Hieruit ziet men, dat de aangehaalde Sanskritverzen in deze beide Hss. even corrupt zijn als in cod. 3134. De ware lezing is n.l.: Yas ya nâgasahasrẹ̣a çatasaṃkhyena wai balam, so' yam nârîm wyapâçritya çete râjâ gatâsuwat (De vorst, wiens kracht die van honderdduizend olifanten evenaarde, die ligt hier nu, tegen eene vrouw aangeleund, alsof het leven hem ontvloden had).

Op p. 38 is eene lacune: Taha i nghulun... Hungsu tan angga manadaha. Hiervoor leest men in cod. 3428s (na Dhṛtarâștra): lawung su tan anggâ hulun mana ḍaha en in cod. $3411^{d}$ : Taha hungsu tan angga hulun manaḍaha. De woorden: apa sangka ning tan manaḍh, die in cod. 3134 volgen op Dhrțarașțra ontbreken zoowel in cod. $3428^{8}$ als in cod. $3411^{\mathrm{d}}$. In alle Hss. is deze plats corrupt.

Op p. 44 r. 11 leze men in plaats van panlâ wtis, zooals cod. 3134 heeft: panas lâwan tis (warmte en koude).

$\mathrm{Na}$ Wirâtanagara (r. 13) volgt in cod. $3428^{\mathrm{s}}$ en $3411^{\mathrm{d}}$ : tk a mara sang. Dropadî enz. (vgl. p. 43 r. 17), hetgeen hier dan ook beter in het verband past.

Op p. 55 moet hinipus (r. 8 v. o.) veranderd worden in hin apus.

Op p. 56 is een groote hiaat achter campakadîmagaurî (r. 2). In cod. $3428^{\mathrm{s}}$ en $3411^{\mathrm{d}}$ volgt daarop deze vertaling : "Kunang rașikî sang kîdi warṇṇa ning câmpakî hinapus, tanpamaḍ̂ ring ayu, anak sang Jarasandha ratu ning Magadha, prasiddhâ kasih sang Sahadewa." Dit is werkelijk de O. Javaansche vertaling van het voorafgaande Sanskritvers 668: I yan tu râjño Mâgadhâdipasya sutâ Jarâsandha iti çrutasya, yawîyaso Mâdrawatîsutasya bhârry yâ. matâ campakadâmagaurî. (Deze echter is de dochter van den vorst van Magadha, genaamd Jarísandha, zij, die bekend is als de vrouw van Mâdrî's jongsten 6e Volgr. VI. 
zoon, geelblank als eene guirlande van campakabloemen.) Daarop volgt in cod. $3428^{\mathrm{s}}$ en $3411^{\mathrm{d}}$ nog een aangehaald Sanskritsvers: Indiwàrasyamatanuḥ sthitaca yehâ parasaṇ̂a mitangga yâsṭih, bhâryya malı̂madrâwiti sutîsya jyaiṣṭ̂sya yaço kamalayatĥkṣ̂. Dit is eene verbastering van vers 669: In dîwaraçy âmatanu hạ sthitĥt tof ca) yaị̂n purâsîna mahîtale ca, bhâry yâ matâ Mûdrawatîsutasya jyeṣthasya se yaṃ (of yaiṣ̂) kamalâyatâkṣ̂. (Zij echter, wier lichaam donkerkleurig als de blauwe lotus is en die vooraan op den grond zit, is bekend als de vrouw van Mâdrî's oudsten zoon, zij met hare lange lotusoogen). Hierop past dan ook de O. Javaansche vertaling (p. 56 r. 3): Kunang sang kadi warṇna ning indîwara, tumungkul tekang anggayașți kḍikḍik, yeka Rtumatî ngaran ira, prasiddha kâsih sang Nakula. De naam van Nakula's vrouw wordt in den Skr. tekst niet genoemd. Rtumatî is een conjectuur voor Retupati, zooals in cod. 3134 staat. Cod. $3428^{\mathrm{s}}$ heeft. Ratuwati en cod. $3411^{d}$ Retuwati.

Op p. 56 r. 9 v. o. moet dawa lâng a priy ah niet veranderd worden in dhawalottarîya, maar in dhawalâ, sa priyâ.

Op p. 67 r. 9 v. o. leze men in plaats van arddha liever: wy artha dahat (zeer doelloos) en r. 8 v. o. in plaats vau tayanta: kîlanta en r. 7 v. o. in plaats van Pâṇ̣ậhala: K hânḍ̂a a dahana.

Op p. 68 r. 3 v. o. moet in plaats van sabhî sira ta gelezen worden: sang Bhagîratha.

Op dezelfde blz. r. 14 leze men in plaats van kamer ing: kabeh maring.

Men ziet dus, dat de vergelijking met de Hss. van dr. v. d. Tuuk vele corrupte plaatsen van cod. 3134 kan herstellen. Een ander maal zullen wij dat gedeelte van het Kụṣnintaka, dat met het Mausalaparwan overeenkomt, uitgeven. 